\title{
O inventário como instrumento de preservação do patrimônio cultural: adequações e usos (des) caracterizadores de seu fim.
}

Yussef Daibert Salomão de Campos*

\section{Resumo}

O patrimônio cultural é alvo de diversos instrumentos jurídicos que buscam sua preservação e promoção. Além da desapropriação, vigilância, registro, apresentamse o tombamento e o inventário como ferramentas comumente utilizadas para atingir esses fins, além de outras formas de acautelamento. Porém, o inventário não possui uma regulamentação infraconstitucional federal como os demais dispositivos. Para tanto, municípios e estados buscam suprimir tal lacuna, exercendo seus respectivos poderes de legislar. Contudo, tem sido atribuído ao inventário efeitos típicos e restritos ao tombamento. Este artigo pretende apresentar essa celeuma, bem como expor posições distintas acerca do inventário como utensílio jurídico, de conhecimento e/ou de preservação, do patrimônio cultural no Brasil.

Palavras-chave: Patrimônio Cultural. Inventário de conhecimento. Inventário de preservação.

The inventory as a tool for cultural heritage preservation: adaptations and uses (un) characterizing its purpose.

Cultural heritage is the subject of several legal instruments that seek its preservation and promotion. Beyond expropriation, monitoring, logging, we present the inventory and the declaration of cultural interest as tools commonly used to achieve these ends, and other forms of precaution. However, the inventory does not have an infra federal regulations as other devices. Therefore, states and municipalities seek to suppress such a gap, exercising their respective powers to legislate. However, it has been assigned to inventory effects and typical restricted to tipping. This article intends to present this stir and expose different positions on the inventory as utensil legal (for knowledge and / or preservation) of cultural heritage in Brazil.

Keywords: Cultural Heritage. Inventory of knowledge. Historic inventory preservation. 


\section{Introdução}

O patrimônio cultural apresenta-se, sempre, como área de embates e disputas, sejam elas bélicas, políticas, sociais, ideológicas, lexicais, ou de outra natureza qualquer. Uma luta quixotesca, na qual o inimigo se transmuta de moinhos para gigantes e de gigantes para moinhos, numa metamorfose singular na qual alguns combatentes têm a nítida sensação de se encontrar rotineiramente do lado mais fraco.

Contra imposições verticais, de cima para baixo, os gestores e estudiosos do patrimônio sujeitam-se a determinações arbitrárias, bem como sujeitam outros a práticas de gestão "adequadas" a cada categoria de bem cultural.

Esse abreviado relato visa apresentar um embate recente que gira em torno dos reais efeitos jurídicos do inventário e sobre a sua natureza. É um conflito, inicialmente acadêmico, mas que já ganha raias da gestão do patrimônio cultural. As partes envolvidas afirmam, peremptoriamente, estarem pautadas na melhor gestão para a proteção e preservação do patrimônio cultural.

\section{Conflitos}

O artigo 216 da Constituição Federal é um dispositivo amplamente exposto em trabalhos científicos que abordam o patrimônio cultural enquanto objeto de pesquisa. Ele conceitua "patrimônio cultural brasileiro", enumera os bens de natureza material e imaterial, determina a possibilidade de punição aos danos e ameaças perpetradas contra ele, distingue o tombamento de sítios quilombolas, e apresenta seus instrumentos de promoção e preservação". Tombamento, registro, inventário, vigilância, desapropriação destacam-se em um rol exemplificativo desses instrumentos, já que o $\S 1^{\circ}$ os lista entre "outras formas de acautelamento".

Tombamento e vigilância ${ }^{2}$ foram regulamentados pelo Decreto-lei n. 25 de 1937, que se propõe a organizar "a proteção do patrimônio histórico e artístico nacional" (BRASIL, 2012), instituindo, inclusive, atribuições ao então Serviço do Patrimônio Histórico e Artístico Nacional (SPHAN). A desapropriação possui como ferramentas 
infraconstitucionais de regulamentação o Decreto-lei n. 3.365, de 1941, que trata das desapropriações por utilidade pública; e a Lei n. 4.132, de 1962, que define os casos de desapropriação por interesse social e dispõe sobre sua aplicação. Já o Decreto n. 3.551, de 2000, institui o registro de bens culturais de natureza imaterial e, cria o Programa Nacional do Patrimônio Imaterial ${ }^{3}$.

O inventário não possui regulamentação infraconstitucional, de âmbito nacional, que estipule normas relativas aos seus efeitos. Dita o artigo 24 da Carta política de 1988 que "Compete à União, aos Estados e ao Distrito Federal legislar concorrentemente sobre [...] VII - proteção ao patrimônio histórico, cultural, artístico, turístico e paisagístico". E o artigo 30 que

Compete aos Municípios: I - legislar sobre assuntos de interesse local; II - suplementar a legislação federal e a estadual no que couber; [...] IX - promover a proteção do patrimônio histórico-cultural local, observada a legislação e a ação fiscalizadora federal e estadual ${ }^{4}$.

Isso significa dizer que, no caso de omissão de norma federal, poderão os estados e municípios legislar sobre a proteção e preservação de seus patrimônios culturais. $\mathrm{O}$ estado de Minas Gerais, por meio do projeto de lei n. 939 de $2011^{5}$, tenta suprir essa ausência quanto à regulamentação do Inventário em seu âmbito. Define, em seu artigo $3^{\circ}$, que:

O inventário consiste na identificação das características, particularidades, histórico e relevância cultural, objetivando a proteção dos bens culturais materiais, públicos ou privados, adotando-se, para sua execução, critérios técnicos objetivos e fundamentados de natureza histórica, artística, arquitetônica, sociológica, paisagística e antropológica, entre outros $\left(\mathrm{ALMG}^{6}, 2012\right)$

Bem fez o legislador mineiro ao definir o inventário como meio de identificação de bens culturais. Para Aurélio Buarque de Holanda Ferreira, "inventariar" significa, entre outros, "descrever miudamente"; e "inventário" a listagem, "relação de bens" (FERREIRA, 2012 $)$. O inventário, na seara patrimonial, é instrumento de conhecimento de bens culturais, seja de natureza material ou imaterial, que subsidia as políticas de preservação do patrimônio cultural; é "levantamento minucioso e completo dos bens culturais" (Unesco $\left.{ }^{8}, 1968^{9}\right)$. Por isso me soa redundante o termo 
"inventário de conhecimento". Para o Instituto Estadual do Patrimônio Histórico e Artístico de Minas Gerais (IEPHA-MG), "o inventário é uma das atividades fundamentais para o estabelecimento e priorização de ações dentro de uma política de preservação efetiva e gestão do patrimônio cultural”. E adiciona: "Toda medida de proteção, intervenção e valorização do patrimônio cultural depende do conhecimento dos acervos existentes" (IEPHA, 2012 ${ }^{10}$ ). Na definição de Marcos Paulo de Souza Miranda,

Sob o ponto de vista prático o inventário consiste na identificação e registro por meio de pesquisa e levantamento das características e particularidades de determinado bem, adotando-se, para sua execução, critérios técnicos objetivos e fundamentados de natureza histórica, artística, arquitetônica, sociológica, paisagística e antropológica, entre outros. Os resultados dos trabalhos de pesquisa para fins de inventário são registrados normalmente em fichas onde há a descrição sucinta do bem cultural, constando informações básicas quanto a sua importância histórica, características físicas, delimitação, estado de conservação, proprietário etc. (MIRANDA, 2008).

Marcos Olender, a partir de pontos cardeais na implementação da política de patrimônio no Brasil - Rodrigo Melo Franco de Andrade e Lúcio Costa - marca a gênese desse instrumento em nosso país:

Institucionalmente, a preocupação com a inventariação do nosso patrimônio encontra-se presente desde os primórdios do SPHAN. Em 1939, Rodrigo Melo Franco de Andrade já apontava para a necessidade desta ação, como pressuposto básico para a proteção do nosso patrimônio. Diz ele: "[...] torna-se necessário proceder pelo país inteiro a um inventário metódico dos bens que pareçam estar nas condições estabelecidas para o tombamento e, em seguida, realizar os estudos requeridos para deliberar sobre a respectiva inscrição". Neste mesmo sentido, Lúcio Costa em seu Plano de Trabalho para a Divisão de Estudos e Tombamento da DPHAN ${ }^{11}$, escrito em 1949, ano no qual assume a direção da citada divisão, aponta para a necessidade vital, para o bom funcionamento da instituição, de coletas de informações para a especificação do "acervo histórico-monumental de interesse artístico que nos incumbe preservar". Coletas estas que se dividem entre aquelas "de natureza técnico-artística" como as de um "inventário de fotografias e plantas", somadas "as decorrentes da observação direta" e as "informações de natureza histórico-elucidativa". A importância deste trabalho é tão grande que Lúcio não se furta em afirmar que, se fosse necessário não se: "[...] vexaria de recomendar a paralisação quase completa das obras em andamento e o cancelamento dos novos serviços [...] a fim de que as verbas da dotação anual do DPHAN fossem integralmente aplicadas, durante dois ou três exercícios 
consecutivos, nessa empresa de colheita e compilação maciça de informações fundamento sobre o qual deverão assentar todas as iniciativas da repartição". Só que, orientado por uma visão historicista do que devia ser considerado patrimônio nacional, ou seja, privilegiando os bens oriundos do nosso passado colonial, Lúcio compara esta coleta de informações com uma "espécie de aventura que deverá ser levada a cabo sem pressa, com o espírito esportivo próprio dos caçadores". A utilização da figura do "caçador", não é, porém a mais apropriada para caracterizar o trabalho do inventariante, pois, "diferente da ideia do explorador, já parte para a aventura sabendo o que deseja encontrar" (12). Lúcio desobedece, pois, uma das regras fundamentais da inventariação, segundo Melot, a de que: "A resposta não é dada antes da questão. A escolha não é feita antes do inventário" (OLENDER, 2010²).

Todavia, o legislador de Minas Gerais atribui ao inventário efeitos estranhos à sua natureza. Apregoa o artigo $4^{\circ}$ do projeto citado acima que:

Os bens culturais inventariados somente poderão ser demolidos, destruídos, deteriorados, descaracterizados ou alterados mediante prévia análise e autorização, tecnicamente justificada, do órgão do patrimônio cultural competente (MINAS GERAIS, 2012).

A atribuição de efeitos do tombamento ao inventário apresenta-se também no parecer para o primeiro turno da tramitação desse projeto, na conclusão por sua juridicidade, pela constitucionalidade e pela legalidade. Afirmam os pareceristas que:

Os proprietários e possuidores de bens inventariados ficarão obrigados a facilitar ao poder público a adoção das medidas necessárias à execução da lei, inclusive o acesso dos órgãos competentes aos bens inventariados, quando necessário. Além disso, deverão conservar e proteger devidamente o bem, adequar sua destinação, seu aproveitamento e sua utilização visando à garantia de sua conservação. (Assembleia Legislativa de Minas Gerais, 2011 ${ }^{13}$ ).

Essa exigência de análise e autorização prévias é natural do tombamento (provisório e definitivo), e não do inventário. Aponta o artigo 17 da lei de tombamento (Decretolei 25 de 1937) que

As coisas tombadas não poderão, em caso nenhum ser destruídas, demolidas ou mutiladas, nem, sem prévia autorização especial do Serviço do Patrimônio Histórico e Artístico Nacional, ser reparadas, pintadas ou restauradas, sob pena de multa de cincoenta por cento do dano causado (sic) (BRASIL, 2012) ${ }^{14}$. 
Assinala, de forma inequívoca, Sônia Rabello de Castro que os efeitos acima descritos são específicos do tombamento (CASTRO, 1991) ${ }^{15}$. São os bens tombados, provisória ou definitivamente, que sofrem essa restrição. Não se pode atribuir ao inventário os efeitos do tombamento. Há uma desordem quanto aos efeitos dos instrumentos de preservação do patrimônio cultural. O espírito do inventário é o de apreciar o bem, pois só se pode proteger aquilo que se conhece, fundamentando, inclusive, um posterior pedido de tombamento. Esse pedido não é uma consequência imediata. Pode-se definir, após o estudo levantado pelo inventário, que determinado bem não seja passível de tombamento, o que mostra a incoerência de se atrelar ao inventário o efeito de restrição da propriedade. A justificativa $^{16}$ apresentada pelo deputado estadual Arlen Santiago ${ }^{17}$, para a aprovação do referido projeto, é a seguinte:

\begin{abstract}
Conquanto o inventário seja instrumento protetivo do patrimônio cultural previsto tanto na Constituição Federal - art. 216, $\S 1^{\circ}$ - quanto na Estadual - art. 209 -, e seja, na prática, amplamente utilizado pelos Municípios e pelo próprio Estado - segundo dados do lepha existem em Minas Gerais cerca de 3.300 bens inventariados como patrimônio cultural -, esse mecanismo de proteção carece ainda, em nosso meio, de normatização infraconstitucional que venha melhor explicitar os seus efeitos jurídicos e os requisitos para sua publicidade, a fim de gerar maior segurança jurídica para a comunidade e o poder público, bem como evitar conflitos de interpretação sobre esse valioso mecanismo de proteção ao patrimônio cultural. Esse projeto objetiva suprir a lacuna até então existente a tal respeito e fortalecer os instrumentos de proteção aos bens de valor cultural existentes em Minas Gerais. Registre-se que no estado do Rio Grande do Sul, por exemplo, a Lei Estadual n. 10.116, de 1994, tratou do inventário como instrumento de preservação do patrimônio cultural - art. 40 -, disciplinando sucintamente seu regime jurídico, o que robusteceu significadamente (sic) a preservação dos bens culturais dessa unidade federativa. Portanto, solicito aos nobres pares desta Casa a aprovação do projeto em tela (SANTIAGO, 2011. p. $90^{18}$ ).
\end{abstract}

Aclarar os efeitos jurídicos do inventário pode apresentar-se como uma justificativa legítima. Mas não possuir lei regulamentadora não impede o Poder Público de utilizar-se do inventário enquanto fonte de conhecimento dos bens culturais alvos de patrimonialização, tampouco gera insegurança jurídica, posto que o inventário esteja previsto constitucionalmente e é prática corriqueira dos órgãos de preservação do patrimônio. O que gerará turbulência no ofício dos gestores do patrimônio é a 
previsível relutância dos proprietários de imóveis a ser inventariados de abrir suas portas para o levantamento de dados desse bem cultural, o que já acontece com os proprietários de imóveis tombados. Assevera Miranda que:

O Inventário e o Tombamento não se confundem. Trata-se de instrumentos de efeitos absolutamente diversos, embora ambos sejam institutos jurídicos vocacionados para a proteção do patrimônio cultural. O inventário é instituto de efeitos jurídicos muito mais brandos do que o tombamento, mostrando-se como uma alternativa interessante para a proteção do patrimônio cultural sem a necessidade Administração Pública de se valer do obtuso e, não raras vezes, impopular instrumento do tombamento (sic) (MIRANDA, 2008).

Porém, não posso concordar com o autor, quando afirma, de forma generalista, que:

\begin{abstract}
Enquanto o tombamento normalmente é utilizado para a proteção somente de bens culturais considerados "notáveis" e "excepcionais", o inventário possui ilimitado espectro de abrangência, podendo ser utilizado para a proteção de bens culturais mais singelos, desde que portadores de referência à memória dos diferentes grupos formadores da nação brasileira (MIRANDA, 2008).
\end{abstract}

O tombamento, por mais que ainda sobrepuje os demais instrumentos como meio de preservação, há muito não se destina somente à excepcionalidade. $O$ inventário instrumentaliza o tombamento, e com ele não se confunde. Mesmo que Miranda reconheça a diferença entre os institutos, ele se apresenta incoerente ao apoiar a ideia errônea de que inventário tem poder restritivo à propriedade, valendo-se do uso indiscriminado do argumento da função social da propriedade e da preservação para as futuras gerações ${ }^{19}$. Esse entendimento equivocado sobre o inventário não só parte do legislador mineiro como do próprio Ministério Público. No $V$ Encontro Nacional do Ministério Público na defesa do Patrimônio Cultural, evento realizado em setembro de 2012 na cidade do Rio de Janeiro, os representantes do Ministério Público Federal e Estaduais, através do que foi nomeado pelo parquet como "Carta do Rio de Janeiro", votaram e apontaram diversas intenções no âmbito de suas atuações em defesa do patrimônio. Entre as 52 apresentadas, as seguintes conclusões (10 a 15) corrompem, assim como o faz o legislador mineiro, o inventário, da seguinte maneira: 
10. Os bens inventariados devem ser conservados adequadamente por seus proprietários, uma vez que ficam submetidos ao regime jurídico específico dos bens culturais protegidos.

11. Os bens inventariados somente poderão ser destruídos, inutilizados, deteriorados ou alterados mediante prévia autorização do órgão responsável pelo ato protetivo, que deve exercer especial vigilância sobre o bem.

12. Os bens inventariados ficam qualificados como objeto material dos crimes previstos nos arts. 62 e 63 da Lei 9.605/98.

13. O instituto do inventário caracteriza-se constitucionalmente como forma autônoma e autoaplicável de proteção ao patrimônio cultural brasileiro.

14. O bem inventariado como patrimônio cultural submete-se a medidas restritivas do livre uso, gozo e disposição do bem.

15. As restrições resultantes do inventário se coadunam com o princípio da função sociocultural da propriedade previsto na Constituição Federal e no Código Civil (art. 1.228, § $\left.1^{\circ}\right)(\operatorname{sic})^{20}$

Mostram, sem sombra de dúvidas, a atribuição de efeitos (medidas restritivas), de justificativas (função social da propriedade) naturais ao tombamento.

Já na esfera legislativa, o parlamentar mineiro exemplifica a necessidade de implementação de seu projeto, ilustrando-o com o exemplo do Rio Grande do Sul, através da Lei n. 10.116, de $1994^{21}$, artigo 40, que celebra que:

Prédios, monumentos, conjuntos urbanos, sítios de valor histórico, artístico, arquitetônico, paisagístico, arqueológico, antropológico, paleontológico, científico, de proteção ou preservação permanente, portadores de referência à identidade, à ação, à memória dos diferentes grupos formadores da sociedade brasileira, não poderão, no, todo ou em parte, ser demolidos, desfigurados ou modificados sem autorização.

$\S 1^{\circ}$ - Para identificação dos elementos a que se refere este artigo, os municípios, com o apoio e a orientação do Estado e da União, realizarão o inventário de seus bens culturais.

$\S 2$ - O plano diretor ou as diretrizes gerais de ocupação do território fixarão a volumetria das edificações localizadas na área de vizinhança ou ambiência dos elementos de proteção ou de preservação permanente, visando a sua integração com o entorno. 
$\S 3^{\circ}$ - O Estado realizará o inventário dos bens culturais de interesse regional ou estadual. (grifo nosso) (RIO GRANDE DO SUL, 2012).

Pode-se advertir que a lei gaúcha, em seu artigo 40 , determina a realização no inventário, mas não atribui a ele os efeitos do tombamento. $O$ deputado mineiro pode utilizar-se dessa lei como fundamentação para a necessidade de legislar sobre o tema, mas não assentar que a lei do Rio Grande do Sul apregoa os sentidos que pretende dar ao inventário.

A atribuição de efeitos do tombamento ao inventário já foi fundamentada, de maneira desarrazoada, a partir do direito comparado ${ }^{22}$. Um exemplo: a França possui dois inventários, o de conhecimento, geral, e o suplementar. O poder legiferante de Minas Gerais provoca uma confusão entre os termos e seus respectivos efeitos, ao importá-los da legislação francesa na tentativa de regulamentar seu inventário. $O$ inventário já utilizado em nosso país, há décadas e em pleno vigor, seria equivalente ao "geral", e não ao "suplementar" como quer o legislador mineiro. Explica Olender que

[...] o "Inventário geral", cuja vocação é "para a descrição e para o conhecimento" não pode ser confundido, como ressalta o próprio Chastel, "com o serviço dos Monumentos Históricos", ou seja, com as ações mais imediatas envolvendo a proteção, como o tombamento e a restauração. O seu maior objetivo é o de contribuir com a ampliação do conhecimento sobre a arte e a cultura, tendo como objetivos específicos: "guiar as organizações de turismo, dar suporte às finalidades do ensino, orientar a pesquisa arqueológica e histórica, e dar, enfim, às comissões responsáveis pelos monumentos históricos e pelo urbanismo, os elementos de ação suficiente".

Este "Inventário Geral" tem função diferente, na própria gestão da preservação do patrimônio cultural francês, daquilo que é denominado de "Inventário suplementar dos monumentos históricos", figura existente, segundo Paulo Ormindo de Azevedo, desde 1948, na legislação francesa, complementando a lei de 31 de dezembro de 1913 sobre os monumentos históricos. Esta figura encontra-se, também, explicitada no "Code $d u$ Patrimoine - Partie Legislative", de 2005 e funciona como uma classificação (como o tombamento é denominado na França) emergencial, complementar e mais flexível. Tanto que a própria legislação diz que, suscitada por uma demanda de intervenção no bem constante deste "inventário suplementar" pelo proprietário do mesmo, a autoridade administrativa terá um prazo (de até cinco anos, dependendo do caso) para proceder à sua 
classificação (ou tombamento) definitiva. Esta figura do "Inventário suplementar" foi transposta, também, para a atual "Lei de Bases do Patrimônio Cultural", de Portugal, promulgada em 8 de setembro de 2001 (OLENDER, 2010).

Alguns exemplos (tanto de legislação estadual quanto municipal), que buscaram suplantar essa lacuna, podem ser aqui expostos.

A lei n. 8.895 de 16 de dezembro de 2003 da Bahia ${ }^{23}$. O artigo 18 determina que "o Inventário para a Preservação será aplicado ao bem cultural, móvel ou imóvel, individualmente ou em conjunto e coleções, tendo por referência o seu caráter reiterativo". E o artigo 20 complementa: "O bem inventariado não poderá sofrer qualquer intervenção sem prévia autorização do IPAC [Instituto do Patrimônio Artístico e Cultural], sob pena de multa e obrigação de reparar os danos causados". Acrescente-se o Decreto n. 10.039, de 2006 que, para Olender:

[...] já em seu primeiro artigo do primeiro capítulo, aponta como um dos "institutos" de proteção do seu patrimônio cultural, o "Inventário para a Preservação", que possui a mesma função preservadora do "Inventário Suplementar" francês, possuindo, inclusive, como no caso do Tombamento, os seus livros de inscrição específicos: os Livros "do Inventário para a Preservação dos Bens Imóveis e Conjuntos" e "do Inventário para a Preservação dos Bens Móveis e Coleções". (OLENDER, 2010).

Já em Porto Alegre ${ }^{24}$, a Lei Complementar 601 de 2008, que dispõe dobre o Inventário do Patrimônio Cultural de Bens Imóveis do Município, prescreve, em seu artigo 10, que "As edificações Inventariadas de Estruturação não podem ser destruídas, mutiladas ou demolidas, sendo dever do proprietário sua preservação e conservação". Vale assinalar que o município de Porto Alegre, por meio da Lei Complementar 434 de 1999, estabelece a seguinte distinção entre edificações de estruturação e de compatibilização:

Art. 14. Integram o Patrimônio Cultural, para efeitos desta Lei, o conjunto de bens imóveis de valor significativo - edificações isoladas ou não, ambiências, parques urbanos e naturais, praças, sítios e áreas remanescentes de quilombos - e paisagens, bem como manifestações culturais - tradições, práticas e referências, denominados de bens intangíveis, que conferem identidade a estes espaços. 
Parágrafo único. As edificações que integram o Patrimônio Cultural são identificadas como Tombadas e Inventariadas de Estruturação ou de Compatibilização, nos termos de lei específica, observado que:

I - de Estruturação é aquela que por seus valores atribui identidade ao espaço, constituindo elemento significativo na estruturação da paisagem onde se localiza;

II - de Compatibilização é aquela que expressa relação significativa com a de Estruturação e seu entorno, cuja volumetria e outros elementos de composição requerem tratamento especial $^{25}$ (PORTO ALEGRE, 2012).

Portanto, inventário, no Brasil, não pode confundir-se com tombamento. Já há dispositivo legal para o tombamento com mais de sete décadas de aplicação. Complemento com o que afirma Olender:

Entendemos que, a partir do momento que, historicamente, o inventário se consolida, no Brasil, como aquilo que denominamos de "inventário de conhecimento ou de identificação" e que, nos últimos anos - principalmente a partir da própria atuação do poder judiciário começa, concomitantemente, a ser utilizado como sinônimo daquilo que na França é denominado de "inventário suplementar" nos cabe, para não incorrermos em uma confusão que será bastante prejudicial para o desenvolvimento das políticas e das práticas de preservação do patrimônio em nosso país, partir para uma melhor denominação das ações hoje empreendidas com este nome. Penso que possuímos, neste caso, duas opções: 1) manter-se a denominação de inventário para aquela ação que se já encontra há mais tempo consolidada e criando-se outra denominação para o citado "tombamento flexível"; ou 2) adjetivar, sempre, os dois tipos de inventário aqui apresentados, denominando-se aquele inventário que entendemos já consolidado como "inventário de conhecimento", "inventário de identificação" ou "inventário de proteção" e o segundo tipo de "inventário para a preservação" (como faz a legislação baiana), ou "inventário de estruturação e de complementação" (como faz a gaúcha), ou algum outro termo que o diferencie do anterior. Só assim, poderemos contribuir para a resolução desta questão que, infelizmente, provoca um desacordo entre diversos e importantes agentes responsáveis pela preservação deste patrimônio (OLENDER, 2010).

Posso aqui citar diversas cartas patrimoniais ${ }^{26}$, que se propõem a indicar diretivas quanto à aplicação do inventário, ou destacar sua importância: Carta de Atenas (Sociedade3 das Nações, 1931); Compromisso de Brasília (10 Encontro dos governadores de Estado, secretários estaduais da área cultural, prefeitos de municípios interessados, presidentes e representantes de instituições culturais, 1970); Compromisso de Salvador (II Encontro de governadores para preservação do 
patrimônio histórico, artístico, arqueológico e natural do Brasil, 1971); Resolução de São Domingos (OEA - Organização dos Estados Americanos, 1974); Declaração de Amsterdã (Conselho da Europa, Ano Europeu do patrimônio arquitetônico, 1975); Conferências (1968 e 1989) e Recomendação (1976) da Unesco; Carta de Lausanne (Icomos/lcahm $\left.{ }^{27}, 1990\right)$, entre outras. Mas aparto duas em especial, uma que releva a função do inventário (Carta de Petrópolis, $1^{\circ}$ Seminário brasileiro para preservação e revitalização de centros históricos, 1987), como outra que aufere seus efeitos (Conferência da Unesco, 1964).

A primeira profere que:

\begin{abstract}
No processo de preservação do $\mathrm{SHU}^{28}$, o inventário como parte dos procedimentos de análise e compreensão da realidade constitui-se na ferramenta básica para o conhecimento do acervo cultural e natural. A realização do inventário com a participação da comunidade proporciona não apenas a obtenção do conhecimento do acervo por ela atribuído ao patrimônio, mas, também, o fortalecimento dos seus vínculos em relação ao patrimônio (CURY, 200. P.286).
\end{abstract}

A segunda articula que, ao se inscrever um bem em um inventário, que esse inventário não tenha "caráter restritivo" (CURY, 2000, p.100).

\title{
3. Conclusão
}

Que se dê nome aos bois para que o tiro não saia pela culatra! Se se pretende criar um novo instrumento de proteção do patrimônio cultural, visto que o rol do $\S 1^{\circ} \mathrm{da}$ Constituição é meramente exemplificativo e permite "outras formas de acautelamento", que se adjetivem os novos inventários surgidos, ou a nascer, mas que não se confunda o inventário (para o conhecimento) com os novos institutos que vem surgindo no país. Claro que o parlamentar, bem como aqueles que protegem o poder restritivo do inventário são legionários em favor do patrimônio. Entretanto, a legislação que se pretende como regulamentadora do inventário na verdade cria outro instrumento de proteção, e não regulamenta o inventário já amplamente utilizado na gestão do patrimônio cultural. 
A lei, em sentido amplo, possibilita a manipulação da memória coletiva ao determinar o que e como deve se preservar os lugares de memória dispersos em um território.

[...], a lei (seja através da Constituição ou das leis a ela dependentes), assim como o censo, o mapa e o museu, atua de forma a criar uma ligação virtual entre aqueles que são classificados em etnias ou raças, que convivem em um território previamente traçado e que compartilham de um passado em comum. É o Estado que manipula essas etnias, esse território e esse passado. E o faz através da lei (CAMPOS, 2013, p.42).

É preciso que se admita que o patrimônio seja um "aparelho ideológico da memória" que "serve de reservatório para alimentar as ficções da história que se constrói do passado" (CANDAU, 2011, p.158-159), que, em busca de uma "memória justa" (RICCEUR, 2007), deve apresentar-se como um "patrimônio ético" (POULOT, 2009, p. 239). O patrimônio é dinâmico e não suporta deturpações de conceitos.

\section{Notas}

(1) 1Art. 216 - Constituem patrimônio cultural brasileiro os bens de natureza material e imaterial, tomados individualmente ou em conjunto, portadores de referência à identidade, à ação, à memória dos diferentes grupos formadores da sociedade brasileira, nos quais se incluem:

I - as formas de expressão;

II - os modos de criar, fazer e viver;

III - as criações científicas, artísticas e tecnológicas;

IV - as obras, objetos, documentos, edificações e demais espaços destinados às manifestações artísticoculturais;

V - os conjuntos urbanos e sítios de valor histórico, paisagístico, artístico, arqueológico, paleontológico, ecológico e científico.

$\S 1^{\circ}$ - O Poder Público, com a colaboração da comunidade, promoverá e protegerá o patrimônio cultural brasileiro, por meio de inventários, registros, vigilância, tombamento e desapropriação, e de outras formas de acautelamento e preservação.

$\S 2^{\circ}$ - Cabem à administração pública, na forma da lei, a gestão da documentação governamental e as providências para franquear sua consulta a quantos dela necessitem.

$\S 3^{\circ}$ - A lei estabelecerá incentivos para a produção e o conhecimento de bens e valores culturais.

$\S 4^{\circ}$ - Os danos e ameaças ao patrimônio cultural serão punidos, na forma da lei.

$\S 5^{\circ}$ - Ficam tombados todos os documentos e os sítios detentores de reminiscências históricas dos antigos quilombos.

$\S 6^{\circ}$ - É facultado aos Estados e ao Distrito Federal vincular a fundo estadual de fomento à cultura até cinco décimos por cento de sua receita tributária líquida, para o financiamento de programas e projetos culturais, vedada a aplicação desses recursos no pagamento de: 
I - despesas com pessoal e encargos sociais;

II - serviço da dívida;

III - qualquer outra despesa corrente não vinculada diretamente aos investimentos ou ações apoiados.

(Disponível em <http://www.dji.com.br/constituicao_federal/cf215a216.htm>). Todas as citações aqui utilizadas, a partir de sítios eletrônicos, foram realizadas em agosto de 2012.

(2) Decreto-lei n. 25/1937, Art. 20. As coisas tombadas ficam sujeitas à vigilância permanente do Serviço do Patrimônio Histórico e Artístico Nacional, que poderá inspecioná-los sempre que fôr julgado conveniente, não podendo os respectivos proprietários ou responsáveis criar obstáculos à inspeção, sob pena de multa de cem mil réis, elevada ao dôbro em caso de reincidência (sic) (disponível em http://www.planalto.gov.br/ccivil_03/decretolei/del0025.htm).

(3) Art. 1 - Fica instituído o Registro de Bens Culturais de Natureza Imaterial que constituem patrimônio cultural brasileiro.

$\S 10$ Esse registro se fará em um dos seguintes livros:

I - Livro de Registro dos Saberes, onde serão inscritos conhecimentos e modos de fazer enraizados no cotidiano das comunidades;

II - Livro de Registro das Celebrações, onde serão inscritos rituais e festas que marcam a vivência coletiva do trabalho, da religiosidade, do entretenimento e de outras práticas da vida social;

III - Livro de Registro das Formas de Expressão, onde serão inscritas manifestações literárias, musicais, plásticas, cênicas e lúdicas;

IV - Livro de Registro dos Lugares, onde serão inscritos mercados, feiras, santuários, praças e demais espaços onde se concentram e reproduzem práticas culturais coletivas.

$\S 20$ - A inscrição num dos livros de registro terá sempre como referência a continuidade histórica do bem e sua relevância nacional para a memória, a identidade e a formação da sociedade brasileira. $\S 30$ - Outros livros de registro poderão ser abertos para a inscrição de bens culturais de natureza imaterial que constituam patrimônio cultural brasileiro e não se enquadrem nos livros definidos no parágrafo primeiro deste artigo. (Disponível em: < http://www.jusbrasil.com.br/legislacao/101954/decreto-3551-00>).

(4) Disponível em < http://www.planalto.gov.br/ccivil_03/constituicao/constitui\%C3\%A7ao.htm>.

(5) Ex-projeto de Lei n. 1.698/2007, apresentado pela Deputada Gláucia Brandão. Disponível em: <http://ws.mp.mg.gov.br/biblio/informa/080414902.htm>.

(6) Assembleia Legislativa de Minas Gerais.

(7) Disponível em: < http://www.aureliopositivo.com.br>.

(8) United Nations Educational, Scientific and Cultural Organization.

(9) Recomendação sobre a conservação dos bens culturais ameaçados pela execução de obras públicas ou privadas - Conferência Geral da Unesco - $15^{\mathrm{a}}$ sessão (CURY, 2000, p.168).

(10) Disponível em: <http://www.ipac.iepha.mg.gov.br/>. 
(11) O SPHAN tem o seu nome alterado para Departamento do Patrimônio Histórico e Artístico Nacional (DPHAN), na década de 1940, até se transformar em IPHAN (Instituto do Patrimônio Histórico e Artístico Nacional). Para aprofundamento: FONSECA, 1997.

(12) Disponível em: <http://www.vitruvius.com.br/revistas/read/arquitextos/11.124/3546>.

(13) Disponível em: <http://ws.mp.mg.gov.br/biblio/informa/270515554.htm>.

(14) Disponível em: <http://www.planalto.gov.br/ccivil_03/decreto-lei/del0025.htm>.

(15) Em obra basilar sobre o tombamento no Brasil, Sônia Rabello de Castro discorre sobre o artigo 17 do decreto lei 25/1937 em seu livro no tópico 6.2.2, denominado "A conservação", inserido no subitem 6.2 "Efeitos específicos do tombamento". (CASTRO, 1991, p.109).

(16) Mesma justificativa aoresentada pela deputada Gláucia Brandão. Ver: Miranda, Marcos P. S. O Inventário como instrumento constitucional de proteção ao patrimônio cultural brasileiro. Disponível em: www.mp.mg.gov.br/portal/public/interno/arquivo/id/3450. Acesso em: mai. 2013.

(17) De autoria do Deputado Sargento Rodrigues, o Projeto de Lei n. 93/2011 dispõe sobre o inventário do patrimônio cultural do Estado e foi distribuído às Comissões de Constituição e Justiça e de Cultura. Em cumprimento ao disposto no art. $173, \S 2^{\circ}$, do Regimento Interno, foi anexado à proposição o Projeto de Lei $\mathrm{n}$. 939/2011, do Deputado Arlen Santiago, que regulamenta o regime jurídico dos bens materiais inventariados como patrimônio cultural no Estado. A Assembleia Legislativa de Minas Gerais concluiu, em 28 de março de 2012, pela aprovação do projeto de lei 93/2011.

(18) Disponível em: <http://ws.mp.mg.gov.br/biblio/informa/080414902.htm>.

(19) "O bem inventariado como patrimônio cultural submete-se - conforme os ditames da Constituição de 1988 a medidas restritivas do livre uso, gozo e disposição do bem, tornando-se, por outro lado, obrigatória a sua preservação e conservação para as presentes e futuras gerações"; "As restrições resultantes do inventário se coadunam com o princípio da função sociocultural da propriedade previsto na Constituição Federal e no Código Civil (art. 1228, $\left.\S 1^{\circ}\right) "($ MIRANDA, 2008).

(20) Disponível em: <http://www.abrampa.org.br/encontro_nacional/index.php>.

(21) Disponível em: <http://www.mp.rs.gov.br/urbanistico/legislacao/id704.htm>.

(22) MIRANDA, 2008.

(23) Regulamentada pelo Decreto n. 10.039, de 03 de julho de 2006. Institui normas de proteção e estímulo à preservação do patrimônio cultural do Estado da Bahia, cria a Comissão de Espaços Preservados e dá outras providências. Disponível em: <http://www.jusbrasil.com.br/legislacao/85799/lei-8895-03-bahia-ba>. 
(24) Disponivel em: <http://www2.portoalegre.rs.gov.br/cgi-bin/nph-brs?

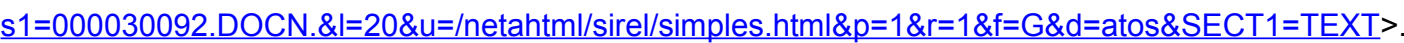

(25) Disponível em:

<http://lproweb.procempa.com.br/pmpa/prefpoa/spm/usu_doc/pddua_com_alteracoes_de_2005.pdf>.

(26) "Esses documentos, muitos dos quais firmados internacionalmente, representam tentativas que vão além do estabelecimento de normas e procedimentos, criando e circunscrevendo conceitos às vezes globais, outras vezes locais" (Coordenadoria de Edições do IPHAN, IN: CURY, 2000).

(27) International Council on Monuments and Sites/ International Scientific Committee on Archaeological Heritage Management.

(28) Sítio Histórico Urbano.

\section{Referências bibliográficas}

CAMPOS, Yussef Daibert Salomão de. Percepção do Intangível: entre genealogias e apropriações do patrimônio cultural imaterial, Belo Horizonte: Arraes Editores, 2013.

CANDAU, Joel. Memória e identidade. São Paulo: Contexto, 2011.

CASTRO, Sônia Rabello de. O estado na preservação de bens culturais: o tombamento. Rio de Janeiro: Renovar, 1991.

CURY, Isabelle. Cartas patrimoniais. Rio de Janeiro: IPHAN, 2000.

MIRANDA, Marcos Paulo de Souza. O inventário como instrumento constitucional de proteção ao patrimônio cultural brasileiro. Jus Navigandi, 2008. Disponível em: <http://jus.com.br/revista/texto/11164/o-inventario-comoinstrumento-constitucional-de-protecao-ao-patrimonio-cultural-brasileiro>. Acesso: em ago. 2012.

NOGUEIRA, Antônio Gilberto Ramos. Inventário e patrimônio cultural no Brasil. História, São Paulo, vol. 26, n. 2, p. 257-268, 2007.

OLENDER, Marcos. Uma "medicina doce do patrimônio". Vitruvius. ano 11, set 2010. Disponível em: <http://www.vitruvius.com.br/revistas/read/arquitextos/11.124/3546>. Acesso em: ago. 2012.

POULOT, Dominique. Uma história do patrimônio no Ocidente. Séculos XVIII - XXI. São Paulo: Estação Liberdade, 2009.

RICOEUR, Paul. A memória, a história, o esquecimento. Campinas: Editora da Unicamp, 2007. 
SANTIAGO, Arlen. In: Diário Oficial do Estado de Minas Gerais (DOEMG) de 7/4/2011, p.90. Disponível em: $<$ http://www.jusbrasil.com.br/diarios/25902036/doemg-executivo-legislativo-07-04-2011-pg-90>. Acesso em: maio 2013

\section{Legislação consultada:}

BRASIL, Constituição Federal de 1988.

Decreto-lei 25 de 1937.

Decreto-lei n. 3.365 de 1941.

Lei n. 4.132 de 1962.

Decreto n. 3.551 de 2000.

ASSEMBLEIA LEGISLATIVA DE MINAS GERAIS, Projeto de lei 939 de 2011.

RIO GRANDE DO SUL, Lei n. 10.116 de 1994.

BAHIA, Lei n. 8.895 de 2003.

Decreto 10039 de 2006.

PORTO ALEGRE, Lei Complementar 601 de 2008.

Lei complementar 434 de 1999.

\section{Créditos:}

Graduado em Direito pela Universidade Federal de Juiz de Fora (UFJF), especialista em Gestão do Patrimônio Cultural pelo Instituto Metodista Granbery / PERMEAR - Programa de Estudos e Revitalização da Memória Arquitetônica Artística, mestre em Memória Social e Patrimônio Cultural pela Universidade Federal de Pelotas (UFPel), doutorando em História (UFJF). E-mail: yussefcampos@yahoo.com.br 